\title{
Políticas públicas para a Educação Básica e suas implicações para o ensino de música
}

\author{
Luis Ricardo Silva Queiroz* \\ Maura Penna**
}

\section{Resumo}

As políticas educacionais vigentes no país e as novas definições para o ensino de música na escola, estabelecidas a partir da Lei n.11.768/2008, têm feito emergir importantes questões para a área de educação musical na atualidade. Considerando essa realidade, este trabalho analisa políticas públicas relacionadas à Educação Básica no Brasil, refletindo acerca de suas implicações para o ensino de música na escola. As discussões realizadas no texto têm como base fontes bibliográficas e documentais relativas a programas e ações direcionadas à Educação Básica no país. A análise aborda objetivos, procedimentos e impactos de propostas de avaliação do desempenho escolar (IDEB), de consolidação e fortalecimento da Educação Básica (FNDE, Fundeb, PDE, PAR); e de integração de diferentes níveis educacionais em torno da formação de professores (Parfor, Prodocência, Pibid). A partir das análises, fica evidente que há um conjunto significativo de programas e ações para a Educação Básica no país e que a educação musical precisa, cada vez mais, participar de forma efetiva na definição e implementação de políticas educacionais que possam fortalecer a área, mas, sobretudo, a formação escolar como um todo.

Palavras-chave: Políticas públicas, Educação Básica, ensino de música.

\section{Public policies for basic education and its implications for the teaching of music}

\begin{abstract}
Current educational policies in the country and the new definitions for the teaching of music in school, established from the law 11.768/2008, have made important issues concerning the area of music education today emerge. Considering this reality, this study analyzes public policies related to basic education in Brazil, reflecting on their implications for the teaching of music in school. The discussions presented in the text are based on literature and documental sources related to programs and actions directed at basic education in the country. The analysis

\footnotetext{
* Professor Adjunto IV do Departamento de Educação Musical da Universidade Federal da Paraíba (UFPB) e Coordenador do Programa de Pós-Graduação em Música.

** Professora Adjunta do Departamento de Educação Musical da Universidade Federal da Paraíba (UFPB).
} 


\section{Luis Ricardo Silva Queiroz - Maura Penna}

covers the objectives, procedures and impacts of proposals of evaluation of educational achievement (IDEB), consolidation and strengthening of basic education (FNDE, FUNDEB, PDE, PAR), and integration of different educational levels regarding the formation of teachers (PARFOR, PRODOCÊNCIA, PIBID). From the analysis, it is evident that there is a significant set of programs and actions for basic education in the country and that music education increasingly needs to participate effectively in the definition and implementation of educational policies that can strengthen the area, but, above all, school education as a whole.

Keywords: Public policies, Basic Education, Teaching of music.

\section{Introdução}

A Educação Básica no Brasil passa por um importante momento de avaliação e redefinição. Em linhas gerais, há um reconhecimento da relevância dessa etapa de formação, tanto para o indivíduo quanto para a sociedade. Nesse sentido, as políticas educacionais brasileiras têm investido consideravelmente em programas diversos que, por diferentes perspectivas, contribuam para o diagnóstico e o fortalecimento dos processos de ensino das escolas.

Por sua vez, a área de educação musical tem ganhado também, no atual momento histórico, amplas possibilidades de expandir e consolidar sua presença na escola, a partir da aprovação da Lei n.11.769/08, que dispõe sobre a obrigatoriedade da música na Educação Básica, como conteúdo obrigatório -embora não exclusivo - do ensino de arte. Essas possibilidades colocam, de imediato, o desafio da formação (inicial e continuada) do professor, em número suficiente e com a capacitação necessária para atuar de modo produtivo nas salas de aula das escolas de Educação Básica, com suas características próprias.

Atualmente, de acordo com as Diretrizes Curriculares Nacionais do Curso de Graduação em Música (BRASIL, 2004), a formação do professor deve se dar na área específica. Aliás, como mostra Penna (2010, p. 136-137), no que concerne à política educacional para o ensino de arte e música, a maior diferença entre a década de 1970 - com a Lei n.5692/71 - e a década de 1990 - com a atual Lei de Diretrizes e Bases da Educação Nacional (BRASIL, 1996) e os documentos curriculares nacionais (BRASIL, 1998) - encontram-se nessas diretrizes para a formação do professor, que implicaram a transformação das licenciaturas plenas em Educação Artística (com habilitação em música) em licenciaturas em música. ${ }^{1}$ No entanto,

[...] por inúmeros fatores, os cursos de licenciatura ainda têm dificuldade em preparar o professor para atuar na Educação Básica. Especialmente na rede pública, as dificuldades da escola básica para a educação mu- 
Políticas públicas para a Educação Básica e suas implicações para o ensino de música

sical são reais - turmas grandes, falta de condições materiais, baixos salários, desvalorização do professor, indisciplina ou violência, etc. Mas não se pode esquecer que essas dificuldades não afetam apenas o ensino de música, pois as outras áreas de conhecimento sofrem também com essas mesmas limitações. [ Assim,] mesmo atualmente, ainda é comum a desistência de professores de música da sala de aula, inclusive em localidades onde já se havia conquistado um espaço para a música no currículo até antes da obrigatoriedade legal. (PENNA, 2010, p. 151)

Para enfrentar tanto as dificuldades nas condições do trabalho docente nas escolas quanto os desafios da formação do professor para a realidade das escolas de Educação Básica, é preciso participar de discussões, análises e ações que transcendem o campo específico do conhecimento musical. Partindo dessa perspectiva, fica evidente que um ponto fundamental para o fortalecimento - e até mesmo a sobrevivência - de nossa área, nos dias de hoje, é sua inserção no âmbito das políticas públicas educacionais, que regulamentam, definem e fomentam a Educação Básica no país. Consideramos ser esse um caminho necessário - se não indispensável - para que a educação musical possa ter um papel mais efetivo na escola, deixando de ser simplesmente coadjuvante na estrutura curricular para ser tornar, de fato, uma área significativa para a formação escolar. Além de uma legitimação epistêmica, metodológica e formativa, precisamos de uma legitimação política, se almejamos sedimentar a música como um componente curricular relevante.

Neste texto, portanto, refletimos acerca das inter-relações do campo da educação musical com o cenário das políticas públicas educacionais vigentes para a Educação Básica. Assim, apresentamos e discutimos diretrizes e ações que possam contribuir para o fortalecimento da música no universo escolar, contemplando os objetivos e direcionamentos pedagógicos da área, mas também dimensões mais abrangentes que permeiam a realidade escolar na atualidade. Para tanto, tomamos como base fontes bibliográficas, nas áreas de música e educação, e ampla pesquisa documental abrangendo programas, leis e outros termos normativos que estabelecem diretrizes e ações relacionadas ao universo das escolas de Educação Básica no país.

\section{O atual cenário das políticas públicas para a Educação Básica no Brasil}

Em linhas gerais, as políticas educacionais definidas para a Educação Básica não contemplam componentes curriculares específicos, sendo estabelecidas em função da formação escolar como um todo. Todavia, áreas como ciência, física, matemática, português e química aparecem, geralmente, como prioritárias em programas e ações que visam o fortalecimento da escola, tendo em vista que são tidas como componentes curriculares de fundamental valor para a formação. 


\section{Luis Ricardo Silva Queiroz - Maura Penna}

Certamente, há uma visão pragmática acerca do papel dessas áreas na sociedade, o que as torna relevantes para a inserção social do indivíduo, seu fortalecimento no campo de trabalho, entre outros aspectos. No entanto, tem-se reconhecido também a necessidade de novos rumos para a formação humana, ética e crítica do indivíduo, buscando-se o fortalecimento de campos emergentes que possam, no cenário da formação escolar, possibilitar um formação plena do sujeito.

Partindo dessa perspectiva de escola e do cenário político educacional delineado no país, emerge uma questão fundamental para o campo da música: de que forma podemos inserir a educação musical no projeto de escola constituído na atual realidade do Brasil e, de maneira mais específica, de que maneira, efetivamente, a área de música pode ser incluída nas perspectivas de avaliação, consolidação, expansão e fortalecimento da educação nacional. Com vistas a refletir sobre tal questão, apresentamos a seguir um panorama geral de programas e ações que fomentam a Educação Básica no Brasil.

\section{Avaliação da Educação Básica}

Um dos principais focos da política de consolidação da Educação Básica no Brasil está no fortalecimento dos programas e critérios de avaliação, entendendo que, sem um diagnóstico significativo da realidade escolar - qualificação profissional, desempenho estudantil, dimensões administrativas e estruturais, entre outros -, não é possível o estabelecimento de ações concretas e a definição de metas que fortaleçam esse nível de ensino.

Merece destaque, neste contexto, a criação em 2007, pelo Ministério da Educação (MEC), do Índice de Desenvolvimento da Educação Básica (IDEB), com o objetivo de medir a qualidade de cada escola e de cada rede de ensino. Esse indicador é calculado com base no desempenho do estudante em avaliações do Instituto Nacional de Estudos e Pesquisa Anísio Teixeira (INEP) e em taxas de aprovação. "Assim, para que o IDEB de uma escola ou rede cresça é preciso que o aluno aprenda, não repita o ano e frequente a sala de aula" (BRASIL, 2011f). O índice é medido a cada dois anos e visa que o país, com base em metas municipais e estaduais, alcance nota seis até 2022. Vale destacar que essa é a nota correspondente à qualidade do ensino em países desenvolvidos. A média brasileira na última avaliação, realizada em 2009, é de 4,6 para os anos iniciais do Ensino Fundamental; 4,0 para os finais do Ensino Fundamental; e 3,6 para o Ensino Médio (BRASIL, 2011g).

Diante dessa realidade, as redes de ensino têm buscado se articular para que possam atender aos desafios da escola e fortalecer o seu IDEB, adequando-se, assim, às perspectivas da educação nacional. Percebe-se, portanto, que a escola vive um momento de "tensão" e, nesse contexto, ações que não fortaleçam diretamente o desenvolvimento escolar certamente não encontraram o respaldo devido na escola de hoje. Nesse sentido, uma questão que emerge 
para a área de música é: em que medida o ensino de música contribui efetivamente para a formação escolar e o desempenho das escolas no âmbito das políticas públicas?

O IDEB pode ser um instrumento importante para a melhoria da qualidade de ensino, ou pelo menos para uma discussão social mais ampla sobre essa importante questão. Nesse sentido, em sua coluna na revista Veja, Gustavo loschpe tem defendido, desde junho de 2011, que este índice seja divulgado visivelmente na entrada de cada escola, o que vem sendo adotado e se tornado proposta de lei em diversos municípios e estados ( IOSCHPE, 2011a, p. 108; 2011b, p. 117). Diz ele: "Em primeiro lugar, todo cidadão tem o direito de saber a qualidade da escola que seu filho frequenta. [...] Em segundo lugar, acredito que essa divulgação pode colaborar para quebrar a inércia da sociedade brasileira em relação às nossas escolas" (IOSCHPE, 2011a, p. 108). E, em sua discussão, apresenta diversos posicionamentos - inclusive de autoridades educacionais - que contestam sua proposta com argumentos até mesmo de que mais importante que o IDEB é a escola ser inclusiva, na medida em que atende alunos de áreas de baixa renda - como se, "para o aluno pobre, o objetivo principal é estar na escola; se aprender, é um bônus". E o articulista contraargumenta: "a inclusão social se dará justamente por meio do aprendizado dos conteúdos e das competências de que esse jovem precisará para ter uma vida produtiva em sociedade" (p. 109).

Concordamos que cabe à escola preparar, de fato, seus alunos, e que o projeto de democratização no acesso ao saber, à cultura e à arte passa por uma escola que seja capaz de efetivamente formar os alunos de ambientes socioculturais desfavorecidos, que têm na escola um importante meio de formação cultural. Neste sentido, endossamos o seguinte posicionamento:

[...] precisamos, sim, de ensino e padrões diferentes para ricos e pobres. Mas é o contrário do preconizado pela maioria: precisamos que a escola dos pobres ensine mais do que a dos ricos. É difícil? Muito. Mas deve ser a nossa meta. Porque, se não for, não estaremos dando igualdade de oportunidades a pessoas que já nascem com tantos déficits na vida. (IOSCHPE, 2011a, p. 112) $)^{2}$

No entanto, temos consciência de que a preocupação com o IDEB e com a melhoria do desempenho da escola na aferição do MEC pode secundarizar o ensino das artes. Temos notícias de tensões que surgem entre gestões preocupadas com tais índices e as instâncias que trabalham com a área artística nas escolas, como é o caso do depoimento a seguir, relativo a mudanças na Secretaria Estadual de Educação de Goiás, estado onde Arte - e mesmo a música, especificamente - já estava incorporada na matriz curricular das escolas da rede, inclusive com a contratação de professores com formação específica (cf. PENNA, 2010, p. 151-152): 
Estamos em tempos difíceis para garantir o espaço do ensino das artes, com a mudança de paradigmas educacionais neste novo governo. Temos disponibilizado muita energia em função de garantir tudo o que havíamos conquistado na área de arte e de música. O governo atual dá muita ênfase à qualidade do ensino expressa em dados estatísticos, mediante a elevação do IDEB, e neste sentido seus investimentos tem sido basicamente nas áreas de português e matemática, desprivilegiando a educação estética. Mas sabemos que a arte trabalha principalmente com a subjetividade humana e faz parte de um processo gradual e contínuo de desenvolvimento, cujos resultados nem sempre são revelados em números. ${ }^{3}$

No entanto, este tipo de dificuldade não pode levar nossa área, centrada unicamente em suas referências, a se opor ao IDEB ou aos programas voltados para a melhoria da qualidade do ensino. Antes, temos que enfrentar a indagação anteriormente apresentada, sobre como o ensino de música pode contribuir para a formação escolar e o desempenho das escolas. Essa questão remete ao "ciclo vicioso" discutido por Penna (2010, p.153) que, na medida em que a educação musical não consegue ocupar de modo efetivo e com práticas significativas os espaços potenciais nas escolas de Educação Básica, torna-se difícil conquistar reconhecimento e valorização. Como consequência, a música deixa de ser considerada como uma parte integrante e necessária da prática escolar, com importante função educativa.

Então, visando romper o círculo vicioso que prende e limita a educação musical, é importante que o professor de música ocupe também este espaço [do ensino de Arte], ajudando a revelar (e consolidar) o valor da música na escola. Cabe esclarecer que, quando se fala de conquistar espaço, não se trata apenas de se fazer presente na escola, mas de fazê-lo de forma competente e efetiva. (PENNA, 2010, p. 156)

Afinal, não é necessário criar uma oposição entre a educação musical e os aspectos medidos pelo IDEB. Acreditamos que nossa meta deva ser contribuir efetivamente para o desenvolvimento global e a formação cultural de um indivíduo que domine não apenas os conhecimentos básicos necessários para sua inserção no mercado de trabalho, mas que tenha o acesso mais amplo possível ao saber e à cultura socialmente produzidos.

\section{Programas de consolidação e fortalecimento da Educação Básica}

Paralelamente ao processo de avaliação, vem sendo articulada uma série de investimentos que visam a melhoria das escolas, destacando-se, nesse sentido, o fortalecimento e a consolidação do Fundo Nacional de Desen- 
Políticas públicas para a Educação Básica e suas implicações para o ensino de música

volvimento da Educação (FNDE). O FNDE é uma "autarquia vinculada ao Ministério da Educação", ${ }_{4}^{4}$ criado por intermédio da Lei n. 5.537, de 21 de novembro de 1968 (BRASIL, 1968) e Decreto-Lei n. 872, de 15 de setembro de 1969 (BRASIL, 1969). Assim, apesar de existir desde o final da década de 1960, o FNDE foi se fortalecendo conjuntamente à valoração e ao investimento na Educação Básica do país, ocupando atualmente um papel de destaque no fomento às políticas públicas, principalmente para o Ensino Fundamental. Nesse sentido, o FNDE tem como finalidade prover recursos e executar ações para o desenvolvimento da educação, visando garantir ensino de qualidade no âmbito da Educação Básica (2011d).

O Fundo visa fortalecer a eficiência na gestão do salário-educação (maior fonte de recursos da Educação Básica), na supervisão dos programas e nas compras governamentais, além da busca permanente de parcerias estratégicas e do fortalecimento institucional. Os recursos do Fundo são direcionados aos estados, ao Distrito Federal, aos municípios e organizações não governamentais para atendimento às escolas públicas de Educação Básica. Entre as suas ações mais importantes estão o Programa Nacional de Alimentação Escolar, o Programa Nacional do Livro Didático, o Programa Dinheiro Direto na Escola (PDDE) e os programas de transporte escolar. É através do PDDE, por exemplo, que é operacionalizado o Programa Mais Educação - que, voltado para a implementação das escolas de tempo integral, desenvolve diversas atividades complementares ao currículo escolar, inclusive no campo da música (cf. BRASIL, 2010; PENNA, 2011).

Como evidenciado anteriormente, o FNDE é, portanto, responsável pela gestão de uma série de iniciativas direcionadas para o contexto da Educação Básica, as quais estabelecem, de forma inter-relacionada, as bases para o financiamento e a estruturação da formação escolar no Brasil. Considerando essa realidade, destacamos, a seguir, três dos principais programas vinculados ao FNDE.

O Fundo de Manutenção e Desenvolvimento da Educação Básica e de Valorização dos Profissionais da Educação (Fundeb) é um programa, vinculado ao FNDE, que atende toda a Educação Básica, da educação infantil ao Ensino Médio e foi estabelecido para substituir o Fundo de Manutenção e Desenvolvimento do Ensino Fundamental e de Valorização do Magistério (Fundef), que vigorou de 1997 a 2006. Criado pela Emenda Constitucional n. 53/ 06 (BRASIL, 2006) e regulamentado pela Lei n. 11.494/07 (BRASIL 2007c) e pelo Decreto n. 6.253/07 (BRASIL, 2007a), o Fundeb está em vigor desde 2007 e seu planejamento se estende até 2020. Este programa oferece um amplo incentivo para a Educação Básica, na medida em que aumenta em cerca de dez vezes o volume anual dos recursos federais investidos nessa modalidade de ensino. Além disso, materializa a visão sistêmica da educação, pois financia todas as etapas da Educação Básica e destina recursos específicos para os programas direcionados a jovens e adultos. A estratégia é equalizar a distribui- 
ção de recursos, de acordo com o desenvolvimento social e econômico das regiões. A destinação dos investimentos é feita de acordo com o número de alunos matriculados na Educação Básica com base em dados do censo escolar do ano anterior.

Outra importante ação para a Educação Básica foi a definição do Plano de Desenvolvimento da Educação (PDE), aprovado em 2007, com o objetivo de promover a melhoria da educação no país, em todas as suas etapas, em um prazo de quinze anos. Tendo a Educação Básica como prioridade, o Plano prevê várias ações que visam identificar e solucionar os problemas que afetam diretamente a Educação brasileira, visando, entre outros aspectos, a melhoria da qualidade de ensino (BRASIL, 2011h). Segundo Saviani, "o PDE foi saudado como um plano que, finalmente, estaria disposto a enfrentar esse problema, focando prioritariamente os níveis de qualidade do ensino ministrado em todas as escolas de Educação Básica do país" (SAVIANI, 2007, p. 1232).

O Plano prevê, também, a implementação de ações visando combater os problemas sociais que inibem o ensino e o aprendizado no país e, neste sentido, defende a educação integral. Assim, o Programa Mais Educação também integra as ações do PDE, que, em seu conjunto, deverão ser desenvolvidas de modo articulado pela União, estados e municípios.

O PDE interliga-se ao Plano de Metas Compromisso Todos pela Educação (BRASIL, 2007b) e ao Plano de Ações Articuladas (PAR) - (BRASIL, 2011e). ${ }^{5}$ Os três planos acontecem de forma integrada e visam estabelecer ações sustentáveis que, a médio e longo prazo, minimizem as dificuldades de formação que ainda permeiam a realidade escolar brasileira, sobretudo na Educação Básica. É importante destacar também a necessidade de articulação entre os diferentes sistemas de ensino previstos nesses programas, o que aponta para a perspectiva de uma política nacional mais integradora, que, mesmo respeitando a autonomia de estados e municípios, estabeleça bases comuns para o fortalecimento da educação nacional.

No que tange ao universo da educação musical, cabe refletir que, como cada sistema de ensino tem autonomia para definir suas prioridades, é fundamental que educadores musicais participem de discussões e, sobretudo, de definições que nortearão as políticas educacionais de cada localidade ao longo de, pelo menos, mais essa década.

\section{Ações integradas: Educação Básica e Ensino Superior}

Outro aspecto importante que pode ser percebido no cenário das políticas educacionais brasileiras é a perspectiva integradora entre diferentes níveis educacionais. Assim, por exemplo, têm sido definidos programas que visam, ao mesmo tempo, fortalecer a formação no Ensino Superior e também na Educação Básica. Nesse sentido, políticas de avaliação, de formação e de in- 
vestimento direcionadas para as escolas transversalizam diferentes níveis de ensino, exigindo que as áreas de conhecimento se articulem em redes que integrem, pelo menos, Educação Básica, graduação e pós-graduação.

Até o ano de 2007, a Coordenação de Aperfeiçoamento de Pessoal de Nível Superior (Capes), órgão vinculado ao Ministério da Educação, dedicava-se exclusivamente ao universo da pós-graduação. Ao longo de mais de meio século de atuação, essa agência desempenhou um papel fundamental na expansão e consolidação da pós-graduação stricto sensu (mestrado e doutorado) no Brasil. Todavia, a partir de 2007, um novo segmento da Capes foi criado com vistas a atender a escola de Educação Básica. Desde então, essa coordenação ampliou seu campo de atuação, passando a formular e fomentar políticas públicas para a qualificação de professores de Ensino Básico.

Por lidar diretamente com a qualificação de professores, os programas hoje geridos na Capes promovem uma clara articulação entre as políticas públicas para o Ensino Superior e as políticas públicas para a Educação Básica. A ideia do governo foi estender a experiência consolidada ao longo de 57 anos de atuação da Capes na pós-graduação para o fortalecimento da Educação Básica no país. Foram criados, assim, diversos programas a serem desenvolvidos no âmbito do Ensino Superior, com vistas a fortalecer a formação profissional e a atuação docente para a Educação Básica. Dentre eles, destacamos o Parfor, Prodocência e Pibid.

O Plano Nacional de Formação de Professores da Educação Básica (Parfor) é resultado de um conjunto de ações do Ministério da Educação, em colaboração com as secretarias de educação dos estados e municípios, envolvendo ainda as instituições públicas de Educação Superior neles sediadas. Tem por objetivo ministrar cursos superiores - gratuitos e de qualidade - a professores das escolas públicas que estão em exercício sem, entretanto, ter uma formação adequada, de acordo com a LDB (BRASIL, 2011a). A partir de 2007, os estados e municípios brasileiros, aderindo ao Plano de Desenvolvimento da Educação, elaboraram seus Planos de Ações Articuladas, contendo diagnósticos dos sistemas locais e suas demandas por formação de professores. A partir de janeiro de 2009, o MEC instituiu a Política Nacional de Formação dos Profissionais do Magistério da Educação Básica, com a finalidade de organizar os planos estratégicos da formação inicial e continuada, com base em arranjos educacionais acordados nos Fóruns Estaduais Permanentes de Apoio à Formação Docente. No Parfor, todas as licenciaturas das áreas de conhecimento da Educação Básica serão ministradas nas modalidades presencial e a distância: cursos de $1^{\text {a }}$ Licenciatura para professores sem graduação; de $2^{\underline{a}}$ Licenciatura para licenciados atuando fora da área de formação; e de Formação Pedagógica, para bacharéis sem licenciatura. Esse programa prevê uma oferta superior a 400 mil vagas novas, envolvendo cerca de 150 instituições de Educação Superior - federais, estaduais, comunitárias e confessionais -, nos 25 estados que aderiram à formação inicial, tendo os cursos iniciado no $2^{\circ}$ semestre de 
2009 e as demais entradas previstas para 2010 e 2011. As instituições formadoras que participam do plano receberão recursos adicionais do MEC.

O Programa de Consolidação das Licenciaturas (Prodocência) visa contribuir para elevar a qualidade dos cursos de licenciatura, por meio de fomento a projetos institucionais, na perspectiva de valorizar a formação e reconhecer a relevância social dos profissionais do magistério da Educação Básica (2011b). O Prodocência seleciona propostas que: a) contemplem novas formas de gestão institucional; b) desenvolvam experiências metodológicas e práticas docentes de caráter inovador; c) apresentem projetos de cooperação entre unidades acadêmicas que elevem a qualidade da formação dos futuros docentes; d) integrem a Educação Superior com a Educação Básica; e) orientem a superação de problemas identificados nas avaliações feitas nos cursos de licenciatura. Podem participar desse programa Instituições Federais de Ensino Superior incluídos os Institutos Federais - e Instituições Estaduais e Municipais de Educação Superior que tenham licenciaturas autorizadas na forma da lei.

O Programa Institucional de Bolsa de Iniciação à Docência (Pibid) foi criado em $2008 \mathrm{com}$ a finalidade de valorizar o magistério e apoiar estudantes de licenciatura, oferecendo bolsas para aprimorar a formação docente e contribuir para elevação do padrão de qualidade da Educação Básica (BRASIL, 2011c). Um dos objetivos do Pibid é a elevação da qualidade das ações acadêmicas voltadas à formação inicial de professores nos cursos de licenciatura das instituições de educação superior, articulada à inserção dos licenciandos no cotidiano de escolas da rede pública de educação, o que promove a integração entre educação superior e Educação Básica. O programa visa também proporcionar aos futuros professores participação em experiências metodológicas, tecnológicas e práticas docentes de caráter inovador e interdisciplinar, que busquem a superação de problemas identificados no processo de ensino-aprendizagem. Incentiva, ainda, as escolas públicas de Educação Básica a se tornarem protagonistas nos processos formativos dos estudantes das licenciaturas, mobilizando seus professores como coformadores dos futuros professores. Podem apresentar proposta às instituições de Educação Superior públicas ou comunitárias (sem fins econômicos), que possuam cursos de licenciatura plena legalmente constituídos e que tenham sua sede e administração no país. São quatro modalidades de concessão de bolsas: bolsistas de iniciação à docência, para estudantes dos cursos de licenciatura plena; bolsistas de supervisão, para os professores das escolas públicas estaduais ou municipais que atuam como coformadores; bolsistas coordenadores institucionais de projeto; e coordenadores de área de conhecimento.

Em linhas gerais, estes programas evidenciam as prioridades e as tendências de desenvolvimento que alicerçam a Educação Básica no país. Vale destacar que a grande maioria dessas ações é de demanda espontânea. Ou seja, abre-se um edital e as áreas de conhecimento manifestam seu interesse em participar, enviando propostas que atendam aos objetivos dos editais. 
Numa breve análise dos resultados dos editais dos últimos anos, fica bastante clara a pouca participação da área de música. Tal fato evidencia que a participação de nossa área no âmbito das políticas públicas ainda não está devidamente consolidada. Assim, torna-se premente discutir, refletir e debater mais profundamente tais questões, tendo em vista que urge buscarmos uma articulação mais ampla com as instâncias educacionais que definem, avaliam e fomentam a Educação Básica no país.

\section{Considerações finais}

A partir das propostas e diretrizes apresentadas anteriormente, alguns aspectos podem ser pensados para o campo da educação musical. $O$ primeiro deles é que a inserção da área no contexto das políticas públicas depende, fundamentalmente, das nossas ações como educadores musicais. Para dialogarmos com as diretrizes e as perspectivas do cenário político-educacional é preciso conhecer e compreender os meandros das políticas públicas do contexto educacional brasileiro e, de forma mais efetiva, participar de sua concepção e aplicação. Consideramos que é preciso agir em duas frentes paralelas, mas inter-relacionadas: 1) conhecer, participar e se adequar aos programas e ações de políticas públicas existentes; 2) ter uma visão crítica e contextual do cenário político consolidado, para propor e articular novos rumos para a educação musical nesse contexto.

Embora possam ter problemas na sua execução, entendemos que as ações político-educacionais discutidas têm direcionamentos adequados, pelo menos em sua concepção, pois estão voltadas para a valorização da Educação Básica e do magistério, valorização esta indispensável para uma real democratização no acesso ao saber, à cultura e à arte. No entanto, "Políticas públicas são viabilizadas de acordo com a incorporação que dela [sic] fazem os grupos em seus contextos sociopolíticos" (MAURícIO, 2009, p. 65). Assim, se não forem de alguma forma reapropriadas, se não forem assumidas como significativas nas instâncias sociais nas quais precisam ser concretizadas, esses programas podem não alcançar os resultados almejados.

Claro está que a questão da efetiva valorização da profissão docente passa também por concursos públicos, planos de carreira, salários dignos, condições de trabalho adequadas, etc. Neste sentido, as demandas do educador musical estão articuladas às dos demais professores, apontando a necessidade de atuação coletiva nessas reivindicações, pois não será somente na especificidade de nossa área que tais questões poderão ser resolvidas ou conquistadas.

Enfim, temos que pensar em políticas públicas para a educação musical ou a educação musical no âmbito das políticas públicas a partir de perspectivas criativas, sólidas e ancoradas nas diretrizes teórico-práticas que norteiam os segmentos político-educacionais brasileiros. Nesse sentido, o planejamento 
em políticas públicas no campo da educação musical tem que ser visto como um processo que atende às necessidades de consolidação e expansão da nossa área, e não como um produto técnico e burocrático simplesmente.

Para isso, precisamos estudar, pesquisar, debater, refletir e elaborar os nossos próprios caminhos. Caminhos inter-relacionados às dimensões já estabelecidas, mas construídos pelas trilhas singulares do nosso campo. Nesse sentido, uma questão importante de ser destacada é que, em lugar de apenas nos adequarmos às perspectivas das políticas públicas existentes, podemos - e na verdade devemos - participar do processo de gestão dessas políticas, o que só é possível a partir de um amplo conhecimento da legislação, das linhas teóricas, das diretrizes e das ações existentes. Essa é a única forma de nós, educadores musicais, dialogarmos e agirmos no contexto das políticas públicas nacionais, fazendo com que a música e a educação musical não sejam apenas áreas coadjuvantes, que precisam se ancorar em outras para conseguir algum tipo de ação política. A partir de uma visão do todo, de projetos consistentes e coerentes e de ações sólidas, podemos, sim, conquistar respaldo e valor para o desenvolvimento de políticas públicas direcionadas para a área de educação musical.

\section{Referências}

BRASIL. Decreto n. 6.253, de 13 de novembro de 2007. Dispõe sobre o Fundo de Manutenção e Desenvolvimento da Educação Básica e de Valorização dos Profissionais da Educação - Fundeb, regulamenta a Lei n. 11.494, de 20 de junho de 2007, e dá outras providências. Brasília, 2007a. Disponível em: <http://www.planalto.gov.br/ccivil_03/_ato2007-2010/2007/Decreto/D6253.htm>. Acesso em: 28 ago. 2011.

. Decreto-Lei n. 872, de 15 de setembro de 1969. Complementa disposições da Lei n. 5.537, de 21 de novembro de 1968, e dá outras providências. Brasília, 1969. Disponível em: <http://www.planalto.gov.br/ccivil_03/decreto-lei/ 1965-1988/Del0872.htm >. Acesso em: 03 set. 2011.

Decreto n. 6.094, de 24 de abril de 2007. Dispõe sobre a implementação do Plano de Metas Compromisso Todos pela Educação, pela União Federal, em regime de colaboração com Municípios, Distrito Federal e Estados, e a participação das famílias e da comunidade, mediante programas e ações de assistência técnica e financeira, visando a mobilização social pela melhoria da qualidade da Educação Básica. Brasília, 2007b. Disponível em: <http://www.planalto.gov.br/ccivil_03/_Ato2007-2010/2007/Decreto/D6094.htm>. Acesso em: 28 ago. 2011.

Emenda Constitucional n. 53, de 19 de dezembro de 2006. Dá nova redação aos arts. $7^{\circ}$, 23, 30, 206, 208, 211 e 212 da Constituição Federal e ao art. 60 do Ato das Disposições Constitucionais Transitórias. Brasília, 2006. Disponível em: <http://www.planalto.gov.br/ccivil_03/constituicao/emendas/emc/ emc53.htm>. Acesso em: 02 set. 2011. 
BRASIL. Lei n. 5.537, de 21 de novembro de 1968. Cria o Instituto Nacional de Desenvolvimento da Educação e Pesquisa (INDEP), e dá outras providências. Brasília, 1968. Disponível em: <http://www.planalto.gov.br/ccivil_03/Leis/ L5537.htm>. Acesso em: 02 set. 2011.

Lei n. 9.394, de 20 de dezembro de 1996. Estabelece as Diretrizes e Bases da Educação Nacional. Brasília, 1996. Disponível em: <http:// www6.senado.gov.br/legislacao/ListaPublicacoes.action?id=102480 > . Acesso em: 10 mar. 2010.

Lei n. 11.494, de 20 de junho de 2007. Regulamenta o Fundo de Manutenção e Desenvolvimento da Educação Básica e de Valorização dos Profissionais da Educação - Fundeb, de que trata o art. 60 do Ato das Disposições Constitucionais Transitórias; altera a Lei n. 10.195, de 14 de fevereiro de 2001; revoga dispositivos das Leis n. 9.424, de 24 de dezembro de 1996, 10.880, de 9 de junho de 2004, e 10.845, de 5 de março de 2004; e dá outras providências. Brasília, 2007c. Disponível em: <http://www.planalto.gov.br/ccivil_03/_ato20072010/2007/Lei/L11494.htm>. Acesso em: 01 set. 2011.

Capes. Plano Nacional de Formação de Professores da Educação Básica - Parfor. Brasília, 2011a. Disponível em: <http://www.capes.gov.br/ educacao-basica/parfor>. Acesso em: 02 set. 2011.

Capes. Programa de Consolidação das Licenciaturas Prodocência. Brasília, 2011b. Disponível em: <http://www.capes.gov.br/ educacao-basica/prodocencia>. Acesso em: 02 set. 2011.

Capes. Programa Institucional de Bolsa de Iniciação à Docência - Pibid. Brasília, 2011c. Disponível em: <http://www.capes.gov.br/educacaobasica/capespibid>. Acesso em: 02 set. 2011.

FNDE. Missão e valores. Brasília, 2011d. Disponível em: <http:// www.fnde.gov.br/index.php/inst-missao-e-objetivos>. Acesso em: 02 set. 2011.

FNDE. Programas - Plano de Ações Articuladas (PAR). Brasília, 2011e. Disponível em: <http://www.fnde.gov.br/index.php/programas-par>. Acesso em: 28 ago. 2011.

BRASIL. INEP. IDEB. Brasília, 2011f. Disponível em: <http://portal.mec.gov.br/ index.php? Itemid=336\&id=180\&option=com_content\&view=article>. Acesso em: 02 set. 2011.

INEP. IDEB: resultados e metas. Brasília, 2011g. Disponível em: <http:/ /ideb.inep.gov.br/resultado/>. Acesso em: 02 set. 2011.

Ministério da Educação. Plano de desenvolvimento da educação: razões, princípios e programas. Brasília, 2011h. Disponível em: <http:// portal.mec.gov.br/arquivos/livro/index.htm\&gt; >. Acesso em: 28 ago. 2011. 
BRASIL. Ministério da Educação e do Desporto. Secretaria de Educação Fundamental. Parâmetros Curriculares Nacionais ( $5^{\mathrm{a}}$ a $8^{\mathrm{a}}$ séries): arte. Brasília, 1998.

. Ministério da Educação. Conselho Nacional de Educação. Conselho Pleno. Resolução $n^{\circ} \mathbf{1}$, de 18 de fevereiro de 2002. Institui Diretrizes Curriculares Nacionais para a Formação de Professores da Educação Básica, em nível superior, curso de licenciatura, de graduação plena. Brasília, 2002. Disponível em: <http://portal.mec.gov.br/cne/arquivos/pdf/rcp01_02.pdf>. Acesso em: 10 set. 2006.

. Ministério da Educação. Conselho Nacional de Educação. Câmara de Educação Superior. Resolução ${ }^{\circ} 2$, de 8 de março de 2004. Aprova as Diretrizes Curriculares Nacionais do Curso de Graduação em Música. Brasília, 2004. Disponível em: http://portal.mec.gov.br/cne/arquivos/pdf/ces0204musica.pdf>. Acesso em: 10 set. 2006.

. Ministério da Educação. Fundo Nacional de Desenvolvimento da Educação. Manual de educação integral para obtenção de apoio financeiro através do Programa Dinheiro Direto na Escola - PDDE, no exercício de 2010. Brasília, 2010. Disponível em: <www.fnde.gov.br/index.php/ ...manualpdde2010educacaointegral/download>. Acesso em: 25 maio 2010.

IOSCHPE, G. Precisamos de educação diferente de acordo com a classe social. Veja. São Paulo, ed. 2225, ano 44, n. 28, p. 108-112, 13 jul. 2011 a.

. A tensa relação entre famílias e escolas. Veja. São Paulo, ed. 2229, ano 44, n. 32, p. 116-117, 10 ago. 2011b.

MAURÍCIO, L. V. Políticas públicas, tempo, escola. In: COELHO, Lígia Martha Coimbra da (Org.). Educação integral em tempo integral: estudos e experiências em processo. Petrópolis: DP et Alli, 2009. p. 53-68.

PENNA, M . Música(s) e seu ensino. 2. ed. rev. ampl. Porto Alegre: Sulina, 2010.

. Educação musical e educação integral: a música no Programa Mais Educação. Revista da ABEM. Porto Alegre, v. 19, n. 25, p. 141-152, jan./jun. 2011.

SAVIANI, D. O Plano de Desenvolvimento da Educação: análise do projeto do MEC. Educação e Sociedade. Campinas, v. 28, n. 100, p. 1231-1255, 2007. Disponível em <http://www.cedes.unicamp.br>. Acesso em: 06 set. 2011. 
Políticas públicas para a Educação Básica e suas implicações para o ensino de música

\section{Notas}

${ }^{1}$ Essas licenciaturas se baseiam, também, nas Diretrizes Curriculares Nacionais para a Formação de Professores da Educação Básica, instituídas pela Resolução n. 1/2002 do CNE (BRASIL, 2002).

2 Sem dúvida, há certa simplificação nesta oposição entre as escolas dos pobres e dos ricos. Mas trata-se de um artigo de uma revista semanal de ampla circulação, que foi justamente selecionado porque evidencia que a discussão sobre a qualidade de nossa Educação Básica não se restringe à academia, mas está presente também na grande imprensa e alcança diversos setores da sociedade. No entanto, encontramos também artigos científicos que se posicionam no mesmo sentido: "[... pode ser] necessário facultar condições desiguais para que as crianças das classes desprestigiadas possam se tornar iguais" (MAURíCIO, 2009, p. 60 - cf. tb. p. 55).

3 Depoimento fornecido por e-mail, em agosto de 2011, pela Profa. Luz Marina de Alcântara, diretora do Centro de Estudo e Pesquisa Ciranda da Arte e responsável por toda a gestão da área de Arte na rede estadual de educação do Estado de Goiás.

${ }^{4}$ Autarquia é uma entidade administrativa autônoma, criada por lei para executar atividades relacionadas à administração pública. Assim, uma autarquia possui personalidade jurídica, patrimônio e receita próprios.

${ }^{5}$ Nos limites deste texto, não é possível detalhar esses programas. A respeito, ver indicações nas referências.

\section{Correspondência}

Luis Ricardo Silva Queiroz - Rua Antônio Carlos de Araújo, 100 apto. 401, CEP: 58045-250 João Pessoa, Paraíba, Brasil.

E-mail: luisrsq@uol.com.br - maurapenna@gmail.com

Recebido em 11 de setembro de 2011

Aprovado em 21 de outubro de 2011 